\title{
Uma teoria da enunciação: Benveniste e Greimas
}

Jose Luiz Fiorin ${ }^{a}$

\begin{abstract}
Resumo
Benveniste formula uma teoria da enunciação, que a concebe como uma instância de mediação entre a língua e a fala. Greimas, na Semântica estrutural, diz que seria necessário, para efetuar uma boa descrição semântica, normalizar o texto, isto é, eliminar dele as categorias da enunciação. Nesse momento, Greimas não tem nenhuma teoria da enunciação. Ela vai aparecer, de forma mais acabada, no Dicionário I, em que ele explicitamente se mostra herdeiro de Benveniste. Greimas herdou de Benveniste uma teoria da enunciação. No entanto, ele reformulou-a para explicitar a construção do texto, precisou-a com a operação de debreagem enunciativa e enunciva e ampliou-a com as operações de embreagem e convocação. Embora tenha herdado de Benveniste sua teoria da enunciação, Greimas deu-lhe uma dimensão que não tinha naquele autor.
\end{abstract}

Palavras-chave: Mediação. Enunciado. Percurso gerativo. Debreagem. Embreagem. Convocação. 
Ferdinand de Saussure pergunta-se se a linguagem pode ser considerada o objeto da linguística. Ele mostra que não, porque a linguagem é um objeto muito heterogêneo: é social e individual; é física, fisiológica e psíquica. Se a linguagem é tudo isso, ela não pode ser objeto da ciência linguística. É preciso construir um objeto homogêneo, para edificar uma ciência. Ele distingue, então, a língua e a fala. A língua para ele é o objeto da linguística. Ela é a parte social da linguagem, é aquele conhecimento internalizado que permite produzir atos de fala (SAUSSURE, 1969, p. 15-25). Não se vai discutir longamente o problema da dicotomia saussuriana língua/fala, mas poder-se-ia dizer que a língua são duas coisas: diferenças fônicas e semânticas e regras de combinação em todos os níveis. A fala é a realização individual daquilo que a língua permite produzir. Saussure não explica como se passa da língua à fala.

A questão mais importante que Benveniste formula, em seus estudos de linguística geral, é aquela que possibilita passar da língua para a fala. Como é que se passa de uma instância para a outra? Como é que esse conhecimento intuitivo na mente do falante se transforma em ato de fala?

Benveniste distingue a língua de seu "exercício" (1976, p. 288). Cada uma dessas instâncias tem diferentes estatutos de realidade: o exercício da linguagem não é simplesmente uma virtualidade, como é a língua. O que permite a passagem do virtual ao realizado é a enunciação, que é a "colocação em funcionamento da língua por um ato individual de utilização" (BENVENISTE, 1974, p. 80) e, portanto, é a instância de mediação entre a língua e o discurso.

Uma instância é um conjunto de categorias que cria um dado domínio. Assim, essa instância de mediação é o conjunto de categorias que permite a passagem da língua para a fala. Quais são essas categorias?

Quando produz um ato de fala, o enunciador apropria-se do conhecimento linguístico e, ao fazê-lo, institui-se como "eu". "Eu" é quem diz "eu", quem toma a palavra. Então, o ato de dizer estabelece um "eu" e, ao mesmo tempo, como esse "eu" fala para alguém, ele constitui simultaneamente um "tu". Esse "eu" fala num determinado espaço, que é o "aqui", o lugar do "eu". A partir desse marco espacial, são estabelecidas todas as diferenças de espaço: por exemplo, em português, aqui, ali, lá, acolá, etc. Além de falar num dado espaço, o "eu" fala num certo 
tempo, o "agora". O "agora" é o momento da fala. "Agora" é o momento em que o "eu" toma a palavra. Benveniste vai dizer que o tempo linguístico é radicalmente diferente do tempo físico e do tempo cronológico, porque o tempo linguístico se constitui na e pela linguagem, ou seja, o "agora" é o momento em que se toma a palavra, não importando em qual momento do tempo físico ele esteja colocado (BENVENISTE, 1974, p. 73).

As categorias que compõem a instância da enunciação são a pessoa, o espaço e o tempo. A enunciação é a instância do ego, hic et nunc, ou seja, do eu, aqui e agora, porque, nela, alguém, num espaço e num tempo criados pela linguagem, toma a palavra e, ao fazê-lo, institui-se como "eu", e dirige-se a outrem, que é instaurado como um "tu". Isso é o conteúdo da enunciação. As categorias de pessoa, de espaço e de tempo vão constituir aquilo que Benveniste vai chamar "o aparelho formal da enunciação" (BENVENISTE, 1974, p. 7988). São essas três categorias linguísticas as responsáveis pela transformação da língua em fala.

Para o linguista francês, essa instância da pessoa, do espaço e do tempo, esse aparelho formal da enunciação é universal, existe em todas as línguas. Mais do que isso, em todas as linguagens (por exemplo, a visual).

Para Benveniste (1976, p. 262), há dois modos básicos de enunciação: o discurso e a história. O primeiro faz-se, em francês, com a primeira pessoa, os verbos relacionados ao presente (presente, passado composto e futuro) e os marcadores espaciais definidos em função do aqui (1976, p. 268); o segundo, com a terceira pessoa, com os tempos não diretamente vinculados ao agora da enunciação (passado simples, futuro do pretérito e mais-que-perfeito) e os marcadores de espaço não determinados em relação ao aqui (1976, p. 262). O imperfeito é comum aos dois planos (1976, p. 268).

Benveniste, em síntese, vai dizer que não se passa da língua para a fala a não ser que se tenha uma instância que permita isso. Essa instância é a enunciação, que é, então, o ato de pôr em funcionamento a língua. Como se põe a língua em atividade? Por uma instância de mediação entre a língua e a fala. O que contém essa instância de mediação? As categorias de pessoa, de espaço e de tempo.

Como se vê, Benveniste, com sua teoria da enunciação, respondeu, com propriedade, a questão que ele tinha formulado 
de como se passa da língua à fala. Quando ele elabora sua resposta, deixa de considerar a fala, no sentido saussuriano, como o reino individual da liberdade e da criação. Na verdade, começa a mostrar-nos que o produto da linguagem é regrado, é social. Saussure pergunta-se num ponto do Curso de linguística geral se a fala tem alguma coisa de regular (1969, p. 144-145). Benveniste vai mostrar que tem. Assim, ele cria um novo objeto para a linguística: o discurso. Até então, a maior unidade de que se ocupava a linguística era o período. O discurso é a produção social da linguagem.

Ao dar um estatuto científico ao exercício da língua, Benveniste volta a inseri-la na vida social, na cultura e na história. O linguista francês explica as operações que se realizam no ato mesmo da enunciação, que se define em relação à língua como um processo (1974, p. 82). A primeira é a mobilização da língua (1974, p. 82). Antes da enunciação, a língua é apenas uma possibilidade. É com o ato de dizer que ela é "efetuada" em uma instância de discurso (1974, p. 81). A segunda é a apropriação, em que "o ato individual pelo qual se utiliza a língua introduz primeiramente o locutor como parâmetro necessário nas condições de enunciação"; essa operação "introduz o que fala em sua fala" (1974, p. 81-82). Benveniste entende essa operação de maneira restrita, pois diz que nela o falante "se apropria do aparelho formal da língua e enuncia sua posição de locutor, de um lado, por índices específicos e, de outro, por meio de processos acessórios" (1974, p. 82). Na verdade, deve-se compreender a apropriação como a assunção da língua em sua totalidade. $\mathrm{O}$ enunciador escolhe formas e combina-as. Como disse Sírio Possenti, “a língua não contém, ela é um aparelho formal de enunciação" (2001, p. 73). O sujeito instala-se no discurso por todas as escolhas e combinações. A terceira é a alocução, em que o enunciador "implanta o outro diante de si" (1974, p. 82). Isso significa que a enunciação é um processo intersubjetivo e, por conseguinte, exige compartilhamento, requer um "consenso pragmático", é uma interação. A quarta operação é a referenciação, em que se expressa uma determinada relação com o mundo (1974, p. 82).

Greimas tem como objeto de suas pesquisas a significação do discurso, manifestado em textos. Tinha que responder uma questão, a das abstrações que se fazem, quando se compreende 
um texto. Por isso, ele herdou o conceito de enunciação de Benveniste e modificou-o, para aplicá-lo ao discurso.

Para entender isso, comecemos com um exemplo: o filme O segredo de Brokeback Mountain, de Ang Lee. Em um nível de abstração muito grande, esse texto trata de um embate entre a natureza e a cultura. A natureza é o domínio da sexualidade, é o domínio do que é instintivo, e a cultura é o domínio das convenções sociais. No filme, há uma ambiguidade sobre o valor desses termos. Temos primeiro uma afirmação da cultura, depois uma negação da cultura, quando os corpos começam a se tocar na montanha, e depois uma afirmação da natureza, a relação entre as personagens. Mas essa natureza nunca é vista como algo positivo. Sempre há uma submissão à ordem da cultura, tanto que os dois cowboys se casam, conforme prescrevem as normas sociais.

O que é da ordem da natureza vai manifestar-se mais na superfície do texto como singularidade, e a cultura, como coletividade. Na história de Jack Twist e Ennis del Mar, os dois cowboys que vivem por mais de vinte anos uma história de amor clandestino, esses dois valores abstratos vão adquirir uma dimensão existencial. O que o filme procura mostrar é que a sociedade é incapaz de aceitar aqueles que fogem à norma, ou seja, que não é capaz de acolher a singularidade. Aparece então a questão do segredo e da mentira. Eles têm que manter a relação deles em segredo por causa das normas sociais e, portanto, têm que mentir. Casam-se, constituem uma família. Aceitam as normas sociais, fazem aquilo que um homem nesse grupo social devia fazer. No entanto, isso é um parecer; no nível do ser, não é exatamente isso o que ocorre. Então se coloca o problema da sanção social, do castigo aos que se recusam a adaptar-se ao que é prescrito: a morte. Essa sanção é recorrente no filme. Ennis del Mar, obrigado pelo pai, viu os corpos mutilados de dois cowboys que se supunha serem homossexuais e imagina que eles foram mortos por seu pai. Mais tarde, Jack Twist tem o mesmo destino. Na hora em que Ennis toma conhecimento de sua morte, a primeira imagem que vem a sua cabeça é a chave de roda com que os cowboys foram mortos. A mulher de Twist nega que ele tenha sido assassinado, diz que ele morrera num acidente de carro provocado por uma explosão do pneu. Ennis não acredita nessa história. Enuncia-se então um problema, que foi estudado por Foucault na História da sexualidade: a 
sexualidade que não tem voz, não tem palavra, não deve ser sequer discursivizada (2009). Então se discursiviza a impotência do indivíduo diante das convenções sociais e se estabelece uma tipologia dos sujeitos. Jack Twist é o inconformado, que resiste ativamente às obrigações sociais. Ele deve fazer uma determinada coisa, mas não quer fazê-la e, por isso, não se satisfaz - e diz isso para o companheiro - com os encontros clandestinos esporádicos e com as esparsas relações sexuais. $\mathrm{O}$ filme mostra-o a procurar prostitutos na fronteira com o México. Ennis del Mar é o sujeito conformado, que aceita passivamente os ditames da sociedade. No conto que deu origem a esse filme, a última fala é dele: "Se não dá para consertar, a gente tem que aguentar" (PROULX, 2006, p. 67).

Observa-se que, nas narrativas, há certos "universais culturais", ou seja, universais em sentido fraco, como o da impotência do indivíduo diante das normas sociais. Esse universal poderia manifestar-se por meio de outra história, não precisaria ser essa, que foi chamada a história dos cowboys gays. Os mesmos universais culturais podem ser manifestados de diferentes maneiras. No filme que estamos analisando, o que é variável são as personagens (dois cowboys), a norma que se transgride (a interdição de relações sexuais entre pessoas do mesmo sexo), o espaço (a montanha, onde eles vão cuidar das ovelhas, fica sendo o espaço da liberdade). Variam também as identidades das personagens: Ennis del Mar é calado, tímido e realista; o outro, falante, sonhador. Figurativizam-se diversamente espaços, personagens, tempos, etc.

Seconsiderarmos que o discursoéo lugar da singularização de universais culturais, devemos entender a enunciação como a instância de mediação entre os elementos mais abstratos e universais e aqueles mais concretos e singulares, que são próprios de cada um dos discursos.

Apresentemos a questão de maneira mais técnica. A semiótica francesa não busca descrever as unidades lexicais, mas a produção e a compreensão dos discursos. Para explicar as abstrações que se fazem no ato da leitura, ela concebe a geração do sentido como um percurso, que vai do mais simples e abstrato ao mais complexo e concreto. Esse percurso gerativo do sentido tem o estatuto de um simulacro metodológico e não um caráter ontológico. Ele apresenta três níveis de profundidade: o fundamental, o narrativo e o discursivo. Os 
dois primeiros constituem as estruturas semionarrativas. No primeiro patamar, estão as oposições semânticas sobre as quais constroem-se o discurso e as operações que se realizam com elas (negação e afirmação); no segundo, descrevem-se os fazeres (transformações de estado), que são um simulacro da ação do homem no mundo e de suas relações com outros homens; no terceiro, concretizam-se temática ou figurativamente as estruturas narrativas e, ao mesmo tempo, elas são actorializadas, temporalizadas e espacializadas. $\mathrm{O}$ nível discursivo será veiculado por um ou vários planos da expressão, produzindo textos, que são a manifestação do discurso (GREIMAS; COURTÉS, 1979, p. 157-160).

Como as estruturas semionarrativas compreendem uma taxinomia e um conjunto de operações sintáxicas elementares, seu modo de existência semiótica tem o estatuto correspondente ao da langue. Por isso, a enunciação é a instância de mediação entre essas estruturas e as do discurso; ela é o lugar do exercício da competência semiótica, constituída das estruturas semionarrativas. Ao mesmo tempo, é a instância de instauração do sujeito da enunciação, que opera num tempo, o agora, e num espaço, o aqui. O lugar do ego-hic-nunc é a esfera de onde se projetam pessoas, espaços e tempos que povoam o enunciado e, ao mesmo tempo, se organizam as figuras do mundo e as configurações discursivas que criam simulacros linguísticos do mundo natural ou explicam-no. A enunciação é um ato, como os outros, e, portanto, comporta uma intencionalidade. É preciso notar, entretanto, que intencionalidade não se confunde com intenção. A semiótica recusa a ideia de intenção de comunicar, porque, para ela, a significação não se reduz somente à dimensão consciente. A intencionalidade é uma relação orientada, por meio da qual o sujeito erige o mundo como objeto e, ao mesmo tempo, constrói a si mesmo. Com efeito, ao mesmo tempo em que o sujeito da enunciação edifica um universo de significação no discurso, estabelece uma imagem de si mesmo com que opera na situação de comunicação (GREIMAS e COURTÉS, 1979, p. 125-127).

A enunciação é o conceito-chave para que o percurso gerativo de sentido seja um modelo harmônico e coeso, pois ela permite a passagem da estrutura ao acontecimento, os dois elementos que ordenam o discurso. 
Em sentido estrito, a enunciação, como em Benveniste, é o lugar do ego, hic et nunc. Em sentido lato, estão submetidos à ordem da enunciação todos os elementos do discurso.

Como se disse acima, se a enunciação é o domínio constitutivo do enunciado, ela é a "instância linguística logicamente pressuposta pela própria existência do enunciado (que comporta seus traços e suas marcas)" (GREIMAS e COURTÉS, 1979, p. 126). O enunciado, por oposição à enunciação, deve ser concebido como o "estado que dela resulta, independentemente de suas dimensões sintagmáticas" (GREIMASe COURTÉS, 1979, p. 123). Ele contém frequentemente elementos que remetem à instância do dizer: de um lado, pronomes pessoais, demonstrativos, possessivos, adjetivos e advérbios apreciativos, dêiticos espaciais e temporais, em síntese, elementos cuja eliminação produz os chamados textos enuncivos, isto é, sem marcas muito explícitas da enunciação; de outro, termos que descrevem o ato de dizer, enunciados e reportados no enunciado (GREIMAS e COURTÉS, 1979, p. 124).

Podem ser produzidos enunciados de dois tipos diferentes. Pode-se dizer, por exemplo, "A Terra é redonda" ou "Eu digo que a Terra é redonda". Isso significa que se pode afastar o "eu" do enunciado e ter-se-ia, então, aquilo que na Teoria Literária se chama uma narrativa em terceira pessoa; ou pode-se instalar o "eu" no interior do enunciado, pode-se projetar a própria enunciação dentro do enunciado e aí se tem uma enunciação enunciada, uma narrativa em primeira pessoa. Quando se diz: "Eu digo que a Terra é redonda", projeta-se o ato de dizer no dito, diz-se a enunciação, enuncia-se o ato de dizer. Quando Greimas e Courtés afirmam que a enunciação é uma instância logicamente pressuposta pelo enunciado (1979, p. 128), o que eles pretendem indicar é que "A Terra é redonda" pressupõe "(Eu digo que) a Terra é redonda", só que esse "eu" não foi projetado no enunciado; que a afirmação "Eu digo que a Terra é redonda" implica "(Eu digo que) Eu digo que a Terra é redonda", o que mostra que o "eu" foi instalado no enunciado. Isso quer dizer que há dois níveis diferentes do "eu": o "eu" pressuposto e o "eu" instaurado no enunciado. $\mathrm{O}$ "eu" pressuposto é chamado enunciador. O enunciador é sempre o "eu" pressuposto, é o autor, não o autor de carne e osso, mas sua imagem construída na totalidade de uma obra. Além disso, há um "eu" que conta a história, é um "eu" que, 
explícita ou implicitamente, está no interior do texto. Esse "eu" não é o enunciador, é um "eu" diferente, é o narrador. Não se pode misturar o narrador com o enunciador, porque isso leva a certas análises psicológicas infundadas do autor, como acusá-lo de expressar seu homossexualismo reprimido ou um complexo de Édipo mal resolvido. Há ainda um terceiro nível do "eu". O narrador dá a palavra a personagens, que falam em discurso direto e, portanto, constituem-se como "eu". Esse "eu" não é o narrador, esse "eu" é a personagem que fala; recebe o nome de interlocutor.

Cada um desses níveis pode desdobrar-se, porque existem vários planos narrativos, histórias dentro de histórias, cada um com seu próprio narrador. Podem-se confundir os níveis: por exemplo, o narrador de Grande sertão: veredas é aquele que dá a palavra a Riobaldo, pois o romance começa com um travessão (-- Nonada. Tiros que o senhor ouviu foram de briga de homem não, Deus esteja.). Riobaldo seria o interlocutor, o que se dirige a alguém, cujas réplicas a sua fala estão implícitas. No entanto, como esse narrador não tem outra marca linguística no texto, pode-se dizer que o interlocutor toma o lugar do narrador.

Há, pois, três níveis de sujeito: o enunciador-autor, o narrador, o interlocutor. Para cada "eu", existe um " $\mathrm{tu}^{\prime}$. O " $\mathrm{tu}$ " do enunciador é o " $\mathrm{tu}$ " pressuposto, o enunciatário, o leitor. $\mathrm{O}$ "tu" do narrador é o narratário; o "tu" do interlocutor é o interlocutário.

O interlocutário é o mais simples de perceber. Quando se lê, no conto Entre duas datas, de Machado de Assis, "- Vejo que fiz mal em falar a você, redarguiu ele rindo", o interlocutor é Duarte e o interlocutário é sua prima, a pessoa com quem ele fala $(1979$, v. II, p. 978)

Onarratárioé um " $t u$ " inscrito, explícita ou implicitamente, no texto. Muitos autores, como Camilo Castelo Branco, por exemplo, operam muito com um narratário explícito no texto. No capítulo XI do Livro Quarto de Os mistérios de Lisboa, há um exemplo:

Os maliciosos quiseram ver na familiaridade do barão um ressaibo adulterino, que o cavalheiro do Porto, ardente Plutarco dos tolos ilustres, julgava não só possível, mas até facto consumado. Neste melindroso ponto, a calúnia não passava do murmurar impotente de meia dúzia de detractores de profissão, e outras tantas senhoras infames, 
que o acaso deslocara do alcouce, e viera sentar nas cadeiras estofadas de Alberto de Magalhães. Desculpai, leitoras susceptíveis, se a frase de legítima indignação, nos ressalta dos bicos da pena. Se tivésseis conhecido Eugénia, se soubésseis quantos anjos de virtude, como Eugénia, aí são mordidos pela víbora cevada nas almas torpes de demónios, infamadores de profissão. (s.d, v. III, p. 46-47)

Nesse trecho, o narrador pede desculpas ao narratário pelo tom indignado que usa para defender Eugênia e explica os motivos que o escusam.

O enunciatário é o leitor para quem o enunciador se dirige. Não é o receptor real, mas uma imagem de leitor criada pela totalidade da obra. Não se confunde o enunciatário com o narratário. Essa distinção remete à possibilidade de uma diferença entre as duas imagens, como ocorre no texto que segue de Machado de Assis.

Começo a arrepender-me deste livro. Não que ele me canse; eu não tenho o que fazer; e, realmente, expedir alguns magros capítulos para esse mundo sempre é tarefa que distrai um pouco da eternidade. Mas o livro é enfadonho, cheira a sepulcro, traz certa contração cadavérica; vício grave, e aliás ínfimo, porque o maior defeito deste livro és tu, leitor. Tu tens pressa de envelhecer, e o livro anda devagar; tu amas a narração direta e nutrida, o estilo regular e fluente, e este livro e meu estilo são como ébrios, guinam à direita e à esquerda, andam e param, resmungam, urram, gargalham, ameaçam o céu, escorregam e caem... (1979: v. I, p. 583)

Há, no texto acima, um narrador e um narratário explícitos. A imagem do narratário é determinada pelo narrador: um leitor comum de romances, que aprecia a narração direta e nutrida (os fatos) e um estilo regular e fluente. O narratário é um leitor dos romances românticos e realistas, em que havia uma linearidade narrativa e não digressões e comentários do narrador. No entanto, se se toma a obra inteira e não essa intervenção pontual do narrador, vai-se observar a real imagem do enunciatário, criada pelo fato de que, na obra machadiana, mais importante que o narrado é a narração, dado que o texto em sua totalidade é um virtuosismo enunciativo, o que confere a Machado uma grande modernidade. O enunciatário é diferente do narratário: é um leitor sofisticado, que não se contenta com as narrativas feitas até a época de Machado e que 
se encanta com a intervenção do narrador a invadir o narrado e a tomar-lhe o lugar.

Note-se que Greimas estuda a enunciação enunciada, isto é, as marcas deixadas pela enunciação no enunciado. Para Greimas e Courtés (1979, p. 79-82, p. 119-121), no entanto, no ato mesmo da enunciação, o falante realiza três operações: a debreagem, a embreagem e a convocação.

A debreagem é um mecanismo de instauração de pessoas, espaços e tempos no enunciado. É uma operação pela qual a instância da enunciação projeta fora dela as categorias ligadas a sua estrutura de base (a pessoa, o tempo e o espaço) para constituir os elementos sobre os quais se assenta o enunciadodiscurso. Dessa forma, ela povoa o enunciado de pessoas, temporaliza-o e espacializa-o.

A debreagem pode ser enunciativa ou enunciva. $\mathrm{Na}$ enunciativa, instalam-se no enunciado os actantes da enunciação $(e u / t u)$, o que cria uma narrativa em que o narrador se explicita como eu e em que pode também enunciar claramente o "leitor" a quem se dirige. Instauram-se também o espaço do aqui e aqueles que se organizam a partir desse marco (aí, ali, lá, acolá). Instituem-se os tempos relacionados diretamente ao presente do ato de dizer (concomitância, anterioridade e posterioridade ao presente). Note-se, por exemplo, o início do poema Tabacaria, de Álvaro de Campos, um dos heterônimos de Fernando Pessoa: "Não sou nada. / Nunca serei nada. / Não posso querer ser nada. / À parte isso, tenho em mim todos os sonhos do mundo." A debreagem enunciativa produz a enunciação enunciada, ou seja, as marcas da enunciação que estão no enunciado.

Na debreagem enunciva, instalam-se no dito os actantes do enunciado (ele), o que cria uma narrativa em que o narrador se ausenta daquilo que diz, fato que é imprecisamente denominado narrativa em terceira pessoa. Nela é como se os fatos se narrassem a si mesmos. Instauram-se também os espaços que não têm nenhuma relação com o espaço enunciativo (por exemplo: no primeiro capítulo da segunda parte de $O$ guarani, de Alencar, aparece a seguinte frase: "No vasto copiar do pouso havia três pessoas contemplando com um certo prazer a luta espantosa dos elementos"; 1964, p. 90). Instituem-se os tempos relacionados seja a um marco temporal pretérito (concomitância, anterioridade e 
posterioridade ao pretérito), seja a um marco temporal futuro (concomitância, anterioridade e posterioridade ao futuro). Esse tipo de debreagem cria um efeito de sentido de objetividade. Efetivamente, se os fatos parece narrarem-se a si mesmos, num espaço não relacionado ao da enunciação e num tempo pretérito ou futuro, que simulam o tempo cósmico, então o texto se tinge de "objetividade". A debreagem enunciva produz o enunciado enunciado, que é assim chamado para mostrar que mesmo o que parece escapar ao ato enunciativo é enunciado.

A embreagem é o efeito de retorno à instância de enunciação, produzido pela suspensão da oposição entre dois termos das categorias de pessoa ou de espaço ou de tempo. Nessa operação, neutralizam-se as diferenças constitutivas dessas categorias, o que leva à utilização de uma pessoa com valor de outra, de um marcador de espaço com sentido de outro ou de um tempo com significado de outro. Observe-se o exemplo que comenta uma fala da cantora Valesca Popozuda:

A carioca Valesca dos Santos gosta de se referir a si mesma na terceira pessoa, como tantos famosos. "Beijinho no Ombro combinou perfeitamente com a Valesca Popozuda", diz, referindo-se ao seu último single. (VEJA, 29/1/2014, p. 78)

Em sua fala, ela neutraliza a oposição entre a primeira e a terceira pessoa, utilizando a terceira com valor de primeira.

Em O coronel e o lobisomem, de José Cândido de Carvalho (1971, p. 239), na passagem "Porta na taramela, ligeirinho pedi ao major notícia de Dona Bebé de Melo: - Seu compadre, onde anda essa beleza", suspende-se a oposição entre aquela e essa, utilizando-se o segundo pronome no lugar do primeiro.

Em Os Lusíadas, aparece o seguinte passo:

Recebe o Capitão alegremente/ O Mouro e toda sua companhia; / Dá-lhe de ricas peças um presente, / Que só pera este efeito já trazia;/ Dá-lhe conserva doce e dá-lhe o ardente,/ Não usado licor, que dá alegria./ Tudo o Mouro contente bem recebe,/ E muito contente come e bebe. (I, 61)

Nele, neutraliza-se a oposição entre o pretérito perfeito (concomitante do pretérito) e o presente (concomitante do presente) e este passa a ser usado em lugar daquele.

A embreagem é um efeito de retorno à instância de enunciação, porque, quando se instalam no enunciado pessoas, espaços e tempos no seu sentido próprio, eles simulam pessoas, 
espaços e tempos do mundo real. No entanto, quando se utiliza uma pessoa no lugar de outra, um tempo com valor de outro, um marcador de espaço com o sentido de outro, notase claramente que pessoa, espaço e tempo são construções da linguagem: a primeira pessoa do plural pode indicar a primeira do singular; a segunda do singular pode ser usada pela primeira do singular; o espaço da primeira pessoa pode apontar para o da terceira; o presente pode tornar-se futuro e assim por diante. As embreagens produzem efeitos de aproximação e distanciamento da instância da enunciação, que se concretizam como subjetividade e objetividade na categoria de pessoa; como presentificação e absenteização na categoria de espaço; como conjunção e deslocação, realidade e virtualidade, inacabamento e não início na categoria de tempo.

É necessário postular teoricamente que toda embreagem pressupõe uma debreagem anterior, porque é preciso haver uma marca que indique ao leitor que uma pessoa, um tempo ou um marcador de espaço estão sendo usados no lugar de outro. Ora, essa marca deve ser descrita como um vestígio da debreagem que precede a embreagem. Na frase “... os dois permanecemos trancados durante toda a viagem que realizamos juntos" (NASSAR, 1997, p. 149), a terceira pessoa do plural está no lugar da primeira do plural e isso é marcado pela concordância verbal, que é explicada pela ocorrência de uma debreagem anterior à embreagem (os dois = eu e meu irmão).

Mais tarde, Greimas acrescenta uma última operação, a convocação (GREIMAS; FONTANILLE, 1993, p. 69-70), que é o chamamento em discurso, é o processo de discursivização de qualquer grandeza semionarrativa disponível. A enunciação convoca as possibilidades ausentes e torna-as presentes. Observe-se que, se pensarmos as operações de enunciação apenas como debreagem e embreagem, temos que operar com um conceito mais restrito de aparelho formal de enunciação. No entanto, com a convocação, a língua, como diz Sírio Possenti, em texto já citado, não contém um aparelho formal de enunciação, ela É um aparelho formal de enunciação, porque todas as formas convocadas para o estabelecimento do enunciado constroem o sujeito enunciador, estando, portanto, submetidas à ordem da enunciação. Não se quer, com isso, desprezar a singularidade das chamadas categorias da enunciação, mas 
chamar a atenção para o fato de que todos os elementos da língua estão subordinados ao domínio da enunciação.

Com as operações de debreagem e de embreagem, Greimas dá uma operacionalidade maior aos conceitos de história e discurso de Benveniste, possibilitando explicar as diferentes possibilidades de discursivização das chamadas categorias da enunciação, a pessoa, o tempo e o espaço.

Greimas, na Semântica estrutural, publicada em 1966, diz que seria necessário, para efetuar uma boa descrição semântica, normalizar o texto, isto é, eliminar dele as categorias da enunciação (GREIMAS, 1973, p. 200-202). Nesse momento, ele não tem nenhuma teoria da enunciação. Ela vai aparecer, de forma mais acabada, no Dicionário I, em que ele explicitamente se mostra herdeiro de Benveniste (GREIMAS; COURTÉS, 1970, p. 126). Greimas herdou de Benveniste uma teoria da enunciação. No entanto, ele reformulou-a para explicitar a construção do texto, precisou-a com as operações de debreagem enunciativa e enunciva e ampliou-a com as operações de embreagem e convocação. Embora tenha herdado de Benveniste sua teoria da enunciação, Greimas deu-lhe uma dimensão que não tinha naquele autor.

\section{REFERÊNCIAS}

ALENCAR, J. de. Obra completa. Rio de Janeiro: Aguilar, v. II, 1964.

ASSIS, M. de. Obra completa. Rio de Janeiro: Nova Aguilar, v. I e II, 1979.

BENVENISTE, E. Problèmes de linguistique générale. Paris: Gallimard, t. 2, 1974.

BENVENISTE, E. Problemas de linguística geral. São Paulo: Nacional/ EDUSP, t. 1, 1976.

BRANCO, C. C. Os mistérios de Lisboa. Lisboa: Publicações Europa-América, v. III, s. d.

CARVALHO, J. C. de. O coronel e o lobisomem. 8 ed. Rio de Janeiro: José Olympio, 1971.

FOUCAULT, M. História da sexualidade. A vontade de saber. São Paulo: Graal, 2009. 
GREIMAS, A. J. Semântica estrutural. São Paulo: Cultrix/ EDUSP, 1973.

GREIMAS, A. J. e COURTÉS, J. Sémiotique: dictionnaire raisonné de la théorie du langage. Paris: Hachette, 1979.

GREIMAS, A. J. e FONTANILLE, J. Semiótica das paixões. Dos estados de coisas aos estados de alma. São Paulo: Ática, 1993.

NASSAR, R. Lavoura arcaica. São Paulo: Companhia das Letras, 1997.

POSSENTI, S. Discurso, estilo e subjetividade. 2. ed. São Paulo: Martins Fontes, 2001.

PROULX, Annie O segredo de Brokeback Mountain. Rio de Janeiro: Intrínseca. 2006.

SAUSSURE, F. de Curso de linguística geral. São Paulo: Cultrix/ EDUSP, 1969. 


\section{Abstract \\ A theory of enunciation: Benveniste and Greimas}

Benveniste formulates a theory of enunciation conceived as an intermediate between language (langue) and speech (parole). In his Structural Semantics, Greimas states that, in order to proceed to a good semantic description, it is necessary to normalize a text, that is, to eliminate from it the categories of enunciation. Greimas did not have then any theory of enunciation. Such theory will appear, in a more complete fashion, in Dictionary I, in which Greimas explicitly shows himself as an heir of Benveniste. Although Greimas inherited from Benveniste a theory of enunciation, he reformulated it, and gave it a dimension it did not have before, in order to make text construction explicit. He made it more precise, with operations of enunciative and enuncive disengagement, and he amplified it, with the engagement and convocation operations.

Keywords: Mediation. Utterance. Generative trajectory. Disengagement. Engagement. Convocation. 